\title{
Evaluation of Lines of Phosphorus and Potassium by High-Resolution Continuum Source Flame Atomic Absorption Spectrometry for Liquid Fertilizer Analysis
}

\author{
Roberta Borges Ferreira, Silvana Ruella Oliveira, Vanessa Pezza Franzini, Alex Virgilio, \\ Jorge Luiz Raposo Junior, and José Anchieta Gomes Neto* \\ UNESP - University Estadual Paulista, Analytical Chemistry Department, \\ Rua Prof. Francisco Degni, s/n, PO Box 355, 14801-970, Araraquara - SP, Brazil
}

\section{INTRODUCTION}

With the acceleration of global fertilizer commerce, simple, accurate, and precise methods for fertilizer analysis are of extreme relevance to assist with the practice recommendations and laboratory guidelines and to manage the quality of the products. Nitrogen, phosphorus $(\mathrm{P})$, and potassium $(\mathrm{K})$, being the major essential plant nutrients (1) and constituents of fertilizers, are among the nutrients most frequently required in fertilizer analysis.

Gravimetry (2), spectrophotometry (3), atomic absorption spectrometry (AAS) (4), inductively coupled plasma optical emission spectrometry (ICP-OES) (5), and flame atomic emission spectrometry (F-AES) (6) are among the techniques mostly employed for P (2-5) and $\mathrm{K}(2,4-6)$ determination. The difficulty in measuring the resonance lines of $P$ in the $167.167 \mathrm{~nm}$ and $178.765 \mathrm{~nm}$ spectral range, and the poor sensitivity of non-resonance lines of $\mathrm{P}$ at $213.618 \mathrm{~nm}, 213.547 \mathrm{~nm}$, and $214.914 \mathrm{~nm}$ may be considered the main drawbacks in the measurement of $\mathrm{P}$ by line source atomic absorption spectrometry (LS-AAS) (7).

Regarding LS-AAS, the determination of various elements is a challenging task because each run requires new operating parameters and calibrations, exchange and conditioning of lamps, all of which are

*Corresponding autbor.

E-mail: : anchieta@iq.unesp.br (J.A.G. Neto)

Tel.: +551633016611

Fax: +551633016692

\section{ABSTRACT}

The usefulness of the side pixel registration approach and molecular absorption was investigated for the determination of phosphorus $(\mathrm{P})$ and potassium $(\mathrm{K})$ in liquid fertilizers by highresolution continuum source flame atomic absorption spectrometry.

The phosphorus oxide (PO) lines at $246.400 \mathrm{~nm}, 247.620$ $\mathrm{nm}, 247.780 \mathrm{~nm}, 324.616 \mathrm{~nm}$, and $327.040 \mathrm{~nm}$ were evaluated. The influence of side pixel registration to extend the linear working range was also investigated by measuring at wings $(404.402 \mathrm{~nm}, 404.406 \mathrm{~nm}$, $404.410 \mathrm{~nm}, 404.418 \mathrm{~nm}$, $404.422 \mathrm{~nm}$ and $404.426 \mathrm{~nm}$ ) of the secondary line for $\mathrm{K}$ at $404.414 \mathrm{~nm}$. For the lines $327.040 \mathrm{~nm}$ and $404.422 \mathrm{~nm}$, analytical curves in the 100-5000 $\mathrm{mg} \mathrm{L}^{-1} \mathrm{P}$ and 50-1000 $\mathrm{mg} \mathrm{L}^{-1} \mathrm{~K}$ ranges were obtained with linear correlations better than 0.999 and 0.995 , respectively.

The proposed method was applied to six liquid fertilizer samples. The found concentrations for $\mathrm{K}$ and $\mathrm{P}$ were in agreement with those obtained by inductively coupled plasma optical emission spectrometry (ICPOES), spectrophotometry, and flame atomic emission spectrometry at the $95 \%$ confidence level.

time-consuming and lead to increased analytical cost. But the applicability of LS-AAS has been further extended with the development of high-resolution continuum source flame atomic absorption spectrometry (HR-CS FAAS) (8). In this concept, a high-resolution double-Echelle monochromator and a charge-coupled device detector with a Xenon (Xe) short-arc lamp continuum source makes sequential multi-element analyses feasible not only by atomic absorption but also by molecular absorption of diatomic molecules (8). The possibility of applying the wavelength-integrated absorbance over the line core, including part of the line wings to enhance sensitivity or measuring at wings of line core (side pixel registration) to extend the linear working range, and correcting background by means of mathematical algorithms, are a particular innovation of this new approach (9-11). For routine laboratories devoted to large-scale analyses, fast sequential multi-element determination is particularly helpful because time and analytical costs may be significantly reduced. Little attention has been given to the use of alternate lines and side peak registration to reduce sensitivity and increase linearity in the sequential multi-element determination by HR-CS FAAS.

This study reports on the evaluation of atomic and molecular lines for phosphorus, and the usefulness of the side pixel registration approach to extend the linear working range for $\mathrm{K}$. The wings of the $\mathrm{K}$ secondary line at $404.414 \mathrm{~nm}$ were measured in order to achieve a simple and fast method for the multi-element determination of $\mathrm{P}$ and $\mathrm{K}$ in liquid fertilizers by HR-CS FAAS. 


\section{EXPERIMENTAL}

\section{Instrumentation}

All measurements were carried out using an Analytik Jena Model ContrAA 300 high-resolution continuum source flame atomic absorption spectrometer, equipped with a Xenon short-arc lamp XBO 301 with a nominal power of $300 \mathrm{~W}$, operating in hot-spot mode as a continuum radiation source (Analytik Jena, Jena, Germany). This new equipment presents a compact high-resolution double-Echelle grating monochromator corresponding to a spectral band width of $<2 \mathrm{pm}$ per pixel in the far ultraviolet range including a charge-coupled device (CCD) array detector. High-purity acetylene (99.7\%, Air Liquid Brazil) was used as fuel gas. The air-acetylene flame was used for atomization of K. The feasibility of using phosphorus oxide (PO) lines in the airacetylene flame was evaluated.

For comparison purposes, the atomic line for $\mathrm{P}$ in acetylenenitrous oxide flame was also tested. All measurements were carried out in four replicates using an injection module (SFS 6) which enables the computer-controlled aspiration of blanks, analytical solutions, and samples. The aspiration rate was fixed at $5.0 \mathrm{~mL} \mathrm{~min}^{-1}$ and the optimized conditions for $\mathrm{K}, \mathrm{P}$, and $\mathrm{PO}$ measurements are summarized in Table I.

\section{Reagents and Standard Solutions}

High purity deionized water obtained using a Millipore Rios $5 \AA$ reverse osmosis and a Millipore Milli- $\mathrm{Q}^{\mathrm{TM}}$ Academic ${ }^{\circledR}$ deionizer system (resistivity $18.2 \mathrm{M} \Omega \mathrm{cm}$, Millipore, Bedford, MA, USA) was used throughout to prepare all solutions. A $10000 \mathrm{mg} \mathrm{L}^{-1}$ P standard stock solution was prepared by dissolving $37.144 \mathrm{~g} \mathrm{NH}_{4} \mathrm{H}_{2} \mathrm{PO}_{4}$ (Mallinckrodt, Xalostoc, México) in water and making the volume up to $1000 \mathrm{~mL}$ with water. A $10,000 \mathrm{mg} \mathrm{L}^{-1} \mathrm{~K}$ standard stock solution was prepared by dissolving $19.068 \mathrm{~g} \mathrm{KCl}$ (Mallinckrodt, Xalostoc, México) in water and making the volume up to $1000 \mathrm{~mL}$ with water. Working standard solutions containing $\mathrm{K}$ (50-5000 $\mathrm{mg} \mathrm{L}^{-1}$ ) and $\mathrm{P}$ (100-5000 $\mathrm{mg} \mathrm{L}^{-1}$ ) were prepared weekly by appropriate dilution of the single standard stock solutions. In the optimized conditions, the addition of ionization suppressor in the working solutions was not necessary. All solutions were stored in

TABLE I

Optimized Instrumental Conditions for $K$ and $P$ Determination by HR-CS FAAS Employing Atomic Lines (213.618 $\mathrm{nm}$ ) and Molecular Lines (246.400 nm, 247.620 nm, $247.780 \mathrm{~nm}$, $324.616 \mathrm{~nm}, 327.040 \mathrm{~nm})$ for $P$, Main (766.491 $\mathrm{nm}$ ) and Secondary (404.414 $\mathrm{nm}$ ) Atomic Lines for $\mathrm{K}$

\begin{tabular}{ccccc}
\hline $\begin{array}{c}\text { Wavelength } \\
(\mathrm{nm})\end{array}$ & $\begin{array}{c}\text { Burner } \\
\text { Height } \\
(\mathrm{mm})\end{array}$ & $\begin{array}{c}\text { Acetylene } \\
\text { Flow Rate } \\
\left(\mathrm{L}^{-1}\right)\end{array}$ & $\begin{array}{c}\text { Air } \\
\text { Flow Rate } \\
\left(\mathrm{L}^{-1}\right)\end{array}$ & $\begin{array}{c}\text { Nitrous } \\
\text { Oxide } \\
\left(\mathrm{L}^{-1}\right)\end{array}$ \\
\hline 213.618 & 4 & 225 & - & 396 \\
246.400 & 7 & 90 & 514 & - \\
247.620 & 9 & 100 & 514 & - \\
247.780 & 6 & 90 & 514 & - \\
324.616 & 7 & 90 & 514 & - \\
327.040 & 5 & 80 & 514 & - \\
404.414 & 5 & 80 & 500 & - \\
766.491 & 5 & 80 & 500 & - \\
\hline
\end{tabular}

\section{Atomic Apectroscopy \\ Vol. 32(2), March/April 2011

high-density polypropylene bottles (Nalgene ${ }^{\circledR}$, Rochester, NY, USA). Plastic bottles and glassware materials were cleaned by soaking in $10 \%$ (v/v) $\mathrm{HNO}_{3}$ for at least 24 hours and rinsing abundantly before use in deionized water.

\section{Sample Preparation}

Liquid fertilizer samples containing potassium phosphite as a source of $\mathrm{K}$ and $\mathrm{P}$ were supplied by Samaritá Industry \& Trading Ltd. (Artur Nogueira, Brazil). Since these samples are completely soluble in water, they were diluted 1:200 (w/v) in deionized water before analysis. A fertilizer reference material (NIST 120c - Phosphate Rock, National Institute of Standards and Technology, Gaithersburg, MD, USA) was digested in a closed microwave system with pressure and temperature control according to a procedure described in the literature (12).

\section{Analytical Procedure}

Measurements were carried out at the main atomic lines for $\mathrm{P}$ $(213.618 \mathrm{~nm})$ and $\mathrm{K}(766.491 \mathrm{~nm})$, alternate lines for PO $(246.400 \mathrm{~nm}$, $247.620 \mathrm{~nm}, 247.780 \mathrm{~nm}, 324.616 \mathrm{~nm}$, $327.040 \mathrm{~nm})$, and a secondary line for K (404.414 nm). The side pixel registration approach was investigated to extend the calibration range for $\mathrm{K}$ without successive dilutions of the samples. This approach was evaluated by measuring in equidistant pixels from the center of the secondary line for $\mathrm{K}$ : $404.402 \mathrm{~nm}, 404.406 \mathrm{~nm}$, $404.410 \mathrm{~nm}, 404.418 \mathrm{~nm}$, $404.422 \mathrm{~nm}, 404.426 \mathrm{~nm}$.

For a $5-\mathrm{mL} \mathrm{min}^{-1}$ sample flow rate, wavelength integrated absorbance equivalent of 3 pixels and calibration within the 100-5000 $\mathrm{mg} \mathrm{L}^{-1} \mathrm{P}$ and 50-5000 $\mathrm{mg} \mathrm{L}^{-1} \mathrm{~K}$ ranges were consistently built up. Recovery tests for spiked samples were done in two levels by adding appropriate aliquots of $10,000 \mathrm{mg} \mathrm{L}^{-1} \mathrm{~K}$ and $\mathrm{P}$ single standard stock solutions in 
diluted fertilizer samples in order to $\mathrm{K}+1000 \mathrm{mg} \mathrm{L}^{-1} \mathrm{P}$ and (b) $1000 \mathrm{mg} \mathrm{L}^{-1}$ $\mathrm{K}+2000 \mathrm{mg} \mathrm{L}^{-1} \mathrm{P}$. All samples were also analyzed by ICP-OES, spectrophotometry and FAES. The limits of detection (LOD) and the limits of quantification (LOQ) for $\mathrm{P}$ and $\mathrm{K}$ were calculated according to IUPAC recommendations (13).

\section{RESULTS AND DISCUSSION}

The determination of $\mathrm{K}$ and $\mathrm{P}$ in liquid fertilizer by LS-FAAS employing a single run is not feasible due to the high concentrations of these analytes in typical samples and the large difference in sensitivity between the main lines for $\mathrm{K}$ and $\mathrm{P}$. Besides, the determination of these elements by LS-AAS using main or secondary lines frequently requires further dilutions of the samples. Preliminary experiments involving analysis of a liquid fertilizer containing $30 \%(\mathrm{~m} / \mathrm{m}) \mathrm{P}_{2} \mathrm{O}_{5}$ and $20 \%$ $(\mathrm{m} / \mathrm{m}) \mathrm{K}_{2} \mathrm{O}$ showed that dilutions of $1: 100$ and $1: 100,000(\mathrm{~m} / \mathrm{v})$ were necessary to adjust, respectively, the $\mathrm{P}$ and $\mathrm{K}$ absorbance within the working concentration range of the calibration plots built up from the main atomic lines for $\mathrm{P}$ and $\mathrm{K}$. For the secondary line of $\mathrm{K}$, dilution of $1: 1000(\mathrm{~m} / \mathrm{v})$ is necessary. High obtain solutions with (a) $500 \mathrm{mg} \mathrm{L}^{-1}$

dilutions of the samples could be avoided by reducing the sensitivity and extending the linear working range for $K$. This strategy may be performed using the side pixel registration approach in HR-CS FAAS. In LS-AAS, less sensitive lines for the determination of major elements are restricted because the weak emission of hollow cathode lamps often does not provide an adequate signal-to-noise ratio (SNR) for good precision. In HR-CS FAAS, the continuum radiation source provides a better SNR than hollow cathode lamps usually found in LSFAAS. Indeed, the use of alternate, less sensitive lines is a better way to reduce sensitivity for determining major elements. In this context, the feasibility of measuring (at the wings of the secondary line) $\mathrm{K}$ at 404.414 $\mathrm{nm}$ by HR-CS FAAS was evaluated for the fast sequential multi-element determination of $\mathrm{P}$ and $\mathrm{K}$ in fertilizers.

\section{Side Pixel Registration Approach}

The influence of side pixel registration on the sensitivity and linearity was investigated after building up calibration plots of absorbance measured at the wavelengths of $404.402 \mathrm{~nm}, 404.406 \mathrm{~nm}, 404.410 \mathrm{~nm}$,

TABLE II

Influence of Side Pixel Registration on the Linear Dynamic Range (LDR), Angular (Slope), and Linear Correlation (R) Coefficients of Analytical Curves, Characteristic Concentration $\left(C_{0}\right)$, Limit of Detection (LOD) and Relative Standard Deviation (RSD) for K at Main $(766.491 \mathrm{~nm})$, Secondary $(404.414 \mathrm{~nm})$, and Alternative $(404.402 \mathrm{~nm}$, $404.406 \mathrm{~nm}, 404.410 \mathrm{~nm}, 404.418 \mathrm{~nm}, 404.422 \mathrm{~nm}, 404.426 \mathrm{~nm})$ Lines

\begin{tabular}{|c|c|c|c|c|c|c|}
\hline $\begin{array}{l}\text { Wavelength } \\
(\mathrm{nm})\end{array}$ & $\begin{array}{c}\mathrm{LDR} \\
\left(\mathrm{mg} \mathrm{L}^{-1}\right)\end{array}$ & $\begin{array}{c}\text { Slope } \\
\left(\text { A.L.mg }{ }^{-1}\right)\end{array}$ & $\mathrm{R}$ & $\begin{array}{c}\mathrm{C}_{\mathrm{o}} \\
\left(\mathrm{mg} \mathrm{L}^{-1}\right)\end{array}$ & $\begin{array}{c}\mathrm{LOD} \\
\left(\mathrm{mg} \mathrm{L}^{-1}\right)\end{array}$ & $\begin{array}{l}\text { RSD } \\
(\%)\end{array}$ \\
\hline 404.402 & $50-1000$ & 0.00054 & 0.9955 & 8 & 0.6 & 4.1 \\
\hline 404.406 & $50-1000$ & 0.00115 & 0.9954 & 4 & 0.2 & 2.2 \\
\hline 404.410 & $50-250$ & 0.00329 & 0.9978 & 1 & 0.05 & 2.0 \\
\hline 404.414 & $50-250$ & 0.00541 & 0.9970 & 1 & 0.04 & 0.9 \\
\hline 404.418 & $50-250$ & 0.00426 & 0.9971 & 1 & 0.07 & 1.5 \\
\hline 404.422 & $50-1000$ & 0.00166 & 0.9955 & 3 & 0.2 & 2.2 \\
\hline 404.426 & $50-1000$ & 0.00022 & 0.9901 & 20 & 1.2 & 2.6 \\
\hline 766.491 & $0.1-2.0$ & 0.14335 & 0.9920 & 0.03 & 0.005 & 1.8 \\
\hline
\end{tabular}

$404.418 \mathrm{~nm}, 404.422 \mathrm{~nm}$, and $404.426 \mathrm{~nm}$ versus the $\mathrm{K}$ analytical solutions in the $50-5000 \mathrm{mg} \mathrm{L}^{-1}$ range. The linear working range, slope, correlation coefficient, characteristic concentration, limit of detection, and relative standard deviation obtained in each wavelength are listed in Table II. For comparison purposes, the figures of merit of the secondary line for $\mathrm{K}$ at $404.414 \mathrm{~nm}$ were also evaluated in order to check the effectiveness of the side pixel registration. Analysis of the results listed in this table reveals that the highest sensitivity for $\mathrm{K}$ was observed for the main line at $766.491 \mathrm{~nm}$, but the superior limit of linear response was for $2.00 \mathrm{mg} \mathrm{L}^{-1}$. The linear dynamic range obtained for the alternative wavelengths of $404.410 \mathrm{~nm}$ and $404.418 \mathrm{~nm}$ extended from 50 to $250 \mathrm{mg} \mathrm{L}^{-1}$, the same interval observed for the secondary line because the selected pixels are relatively close to the line core of $404.414 \mathrm{~nm}$. Other wavelengths tested for $\mathrm{K}$ allowed extending the linear response up to $1000 \mathrm{mg} \mathrm{L}^{-1}$. The use of side pixels increased the distance to the line core of $404.414 \mathrm{~nm}$, resulting in reduced sensitivity and higher limit of detection (Table II). The linearity was slightly affected with the distance to the line core: correlation coefficients of all analytical curves were always better than 0.99. The RSD increased from $0.9 \%$ to $4.1 \%$ and $0.9 \%$ to $2.6 \%$ when the wavelength changed from $404.414 \mathrm{~nm}$ to $404.402 \mathrm{~nm}$ and from $404.414 \mathrm{~nm}$ to $404.426 \mathrm{~nm}$, respectively. The calibration curves for $\mathrm{K}$ within the 50-1000 $\mathrm{mg} \mathrm{L}^{-1}$ concentration range for the lines $404.402 \mathrm{~nm}$, $404.406 \mathrm{~nm}, 404.422 \mathrm{~nm}$, and $404.426 \mathrm{~nm}$ could be used. But lines $404.402 \mathrm{~nm}$ and $404.426 \mathrm{~nm}$ presented, respectively, either the highest RSD (4.1\%) or the lowest linear correlation coefficient (0.9901). However, measurements at side pixels corresponding to $404.406 \mathrm{~nm}$ and $404.422 \mathrm{~nm}$ were 
carried out with good precision $(\mathrm{RSD} \approx 2 \%)$. The LOD was about $0.2 \mathrm{mg} \mathrm{L}^{-1}$ for both lines. Therefore, the alternate lines at $404.406 \mathrm{~nm}$ and $404.422 \mathrm{~nm}$ can be used for accurate determination of $\mathrm{K}$ in fertilizers using a single dilution of the samples.

\section{Evaluation of Atomic and Molecular Absorption Lines for Phosphorus}

A detailed spectrum of PO bands within the $244 \mathrm{~nm}-249 \mathrm{~nm}$ and $324 \mathrm{~nm}$ - $328 \mathrm{~nm}$ wavelength ranges showed several bands with narrow spectral profiles appropriate for the determination of phosphorus (7). Taking into consideration these findings, the main parameters affecting the production of PO molecules in the air-acetylene flame were investigated in this work. The surements at the wavelengths $246.400 \mathrm{~nm}, 247.620 \mathrm{~nm}, 247.780 \mathrm{~nm}$, $324.616 \mathrm{~nm}$, and $327.040 \mathrm{~nm}$ are summarized in Table I. The main analytical figures of merit for the determination of $\mathrm{P}$ by molecular absorption spectrometry are summarized in Table III. The data refer to monitoring of the working solutions within the $100-5000 \mathrm{mg} \mathrm{L}^{-1} \mathrm{P}$ concentration range at the wavelength integrated absorbance equivalent to 3 pixels $(\mathrm{CP} \pm 1)$. For optimized conditions for PO mea-

comparison purposes, the figures of merit of the atomic line for $\mathrm{P}$ at $213.618 \mathrm{~nm}$ in the acetylene-nitrous oxide flame were included in Table III. Analysis of Table III reveals that the highest sensitivity for $\mathrm{P}$ was observed for the atomic line at $213.618 \mathrm{~nm}$, but the superior limit of linear response was $2000 \mathrm{mg} \mathrm{L}^{-1}$. It should be pointed out that although this line presents suitable sensitivity, the molecular lines are more attractive than the atomic lines because PO molecules may be produced in the air-acetylene flame also required for $\mathrm{K}$ determination. Indeed, the use of a specific burner and the need for disassembling the burner head for cleaning during analysis may also be considered inconvenient. In addition, the line at $213.618 \mathrm{~nm}$ provided the worst precision (8.6\%). The linear dynamic range obtained for the $\mathrm{PO}$ lines at $246.400 \mathrm{~nm}$ and $247.780 \mathrm{~nm}$ ranged from 100-3000 $\mathrm{mg} \mathrm{L}^{-1}$ and 100-4000 $\mathrm{mg} \mathrm{L}^{-1}$, respectively. And the wavelengths of $247.620 \mathrm{~nm}$, $324.616 \mathrm{~nm}$, and $327.040 \mathrm{~nm}$ extended the linear response up to $5000 \mathrm{mg} \mathrm{L}^{-1}$.

The linearity of calibration plots was unaffected by varying the PO wavelengths: correlation coefficients of all analytical curves were higher than 0.998. The wavelengths at $247.620 \mathrm{~nm}, 324.616 \mathrm{~nm}$, and

TABLE III

Linear Dynamic Range (LDR), Angular (Slope), and Linear Correlation (R) Coefficients of Analytical Curves, Characteristic Concentration $\left(C_{0}\right)$, Limit of Detection (LOD), and Relative Standard Deviation (RSD) Obtained for Atomic (213.618 $\mathrm{nm}$ ) and Molecular $(246.400 \mathrm{~nm}$, 247.620 nm, 247.780 nm, $324.616 \mathrm{~nm}$, and $327.040 \mathrm{~nm}$ ) Lines for the Determination of Phosphorus by HR-CS FAAS

\begin{tabular}{ccccccc}
\hline $\begin{array}{c}\text { Wavelength } \\
(\mathrm{nm})\end{array}$ & $\begin{array}{c}\mathrm{LDR} \\
\left(\mathrm{mg} \mathrm{L}^{-1}\right)\end{array}$ & $\begin{array}{c}\text { Slope } \\
\left(\mathrm{A} . \mathrm{L} . \mathrm{mg}^{-1}\right)\end{array}$ & $\mathrm{R}$ & $\begin{array}{c}\mathrm{C}_{\mathrm{o}} \\
\left(\mathrm{mg} \mathrm{L}^{-1}\right)\end{array}$ & $\begin{array}{c}\text { LOD } \\
\left(\mathrm{mg} \mathrm{L}^{-1}\right)\end{array}$ & $\begin{array}{c}\mathrm{RSD} \\
(\%)\end{array}$ \\
\hline 213.618 & $100-2000$ & $3.1 \cdot 10^{-5}$ & 0.9989 & 140 & 55 & $2.5-8.6$ \\
246.400 & $100-3000$ & $3.4 \cdot 10^{-5}$ & 0.9987 & 128 & 20 & $1.7-4.4$ \\
247.620 & $100-5000$ & $2.3 \cdot 10^{-5}$ & 0.9995 & 192 & 17 & $0.6-7.6$ \\
247.780 & $100-4000$ & $2.5 \cdot 10^{-5}$ & 0.9997 & 173 & 12 & $1.0-4.2$ \\
324.616 & $100-5000$ & $2.0 \cdot 10^{-5}$ & 0.9998 & 217 & 18 & $0.6-4.7$ \\
327.040 & $100-5000$ & $1.9 \cdot 10^{-5}$ & 0.9999 & 233 & 20 & $0.5-4.9$ \\
\hline
\end{tabular}

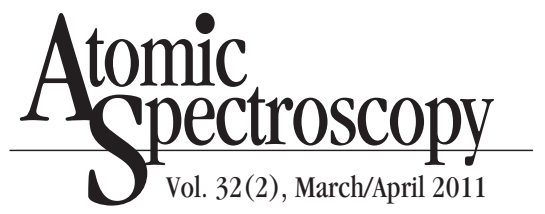

$327.040 \mathrm{~nm}$ presented the widest linear dynamic range and could be used to determine $\mathrm{P}$. The low precision of the line at $247.620 \mathrm{~nm}$ (RSD $=7.6 \%$ ) and the possibility of spectral interference of $\mathrm{Fe}(324.602 \mathrm{~nm})$ on the PO line at $324.616 \mathrm{~nm}$ were taken into consideration in selecting $327.040 \mathrm{~nm}$ as the optimum wavelength for $\mathrm{P}$ determination.

\section{Analyses of Samples}

After evaluation of all of the selected lines, the procedure was optimized and applied to the sequential multi-element determination of $\mathrm{P}$ and $\mathrm{K}$ in different N-P-K formulations of the liquid fertilizers. The PO molecular line for $\mathrm{P}$ at the $327.040 \mathrm{~nm}$ line was used. For wavelength integrated absorbance of 3 pixels and the aspiration rate of the nebulizer at $5.0 \mathrm{~mL} \mathrm{~min}{ }^{-1}$, analytical curves in the 100-5000 $\mathrm{mg} \mathrm{L}^{-1} \mathrm{P}$ concentration range were always obtained with linearity better than 0.999. The determination of $\mathrm{K}$ was carried out using the side pixel registration at $404.406 \mathrm{~nm}$ and $404.422 \mathrm{~nm}$. Calibration curves within 50-1000 $\mathrm{mg} \mathrm{L}^{-1} \mathrm{~K}$ were typically obtained with linear correlation coefficients of $\mathrm{r}=0.9954$ $(404.406 \mathrm{~nm})$ and $\mathrm{r}=0.9955$ (404.422 nm).

Phosphorus and $\mathrm{K}$ were also determined in fertilizer reference material NIST 120c Phosphate Rock. The results for $\mathrm{P}$ and $\mathrm{K}$ determination were in agreement at the 95\% confidence level (paired $t$-test) with certified values (Table IV). The results for $\mathrm{K}$, using the side pixel registration at $404.406 \mathrm{~nm}$ and $404.422 \mathrm{~nm}$, were in agreement with those obtained for the secondary line. Thus, using the side pixel registration approach is feasible in order to extend the linear working range and to determine $\mathrm{K}$ together with $\mathrm{P}$ in fertilizers. Indeed, six fertilizer samples were analyzed by the proposed method. The found concentrations for $\mathrm{P}$ and $\mathrm{K}$ by the proposed method were in 
TABLE IV

Results (Mean \pm Confidence Interval, $95 \%$ Confidence Level) for $\mathbf{P}\left[\left(\%(w / w) P_{2} \mathrm{O}_{5}\right]\right.$ and $\mathrm{K}\left[\%(\mathrm{w} / \mathrm{w}) \mathrm{K}_{2} \mathrm{O}\right]$ in Liquid Fertilizers as Determined $(\mathrm{n}=4)$

by the Proposed HR-CS FAAS Method and by ICP OES, UV/VIS, and Flame Photometer (FF)

(Data for HR-CS FAAS Refer to Measurements at Wavelengths $404.406 \mathrm{~nm}$ and $327.040 \mathrm{~nm}$ )

\begin{tabular}{|c|c|c|c|c|c|c|}
\hline \multirow[t]{2}{*}{ Sample } & \multicolumn{2}{|c|}{ HR-CS FAAS } & \multicolumn{2}{|c|}{ ICP OES $^{c}$} & \multirow{2}{*}{$\begin{array}{c}\text { UV/VIS }^{\mathrm{d}} \\
\mathrm{P} \\
\end{array}$} & \multirow{2}{*}{$\begin{array}{c}\mathrm{FF}^{\mathrm{e}} \\
\mathrm{K}\end{array}$} \\
\hline & $\mathrm{P}$ & K & $\mathrm{P}$ & $\mathrm{K}$ & & \\
\hline $1^{\mathrm{a}}$ & $20.2 \pm 0.9$ & $19.2 \pm 1.7$ & $19.7 \pm 1.4$ & $20.2 \pm 0.9$ & $20.8 \pm 1.2$ & $19.8 \pm 0.4$ \\
\hline $2^{\mathrm{a}}$ & $28.3 \pm 0.8$ & $18.8 \pm 1.3$ & $28.9 \pm 1.8$ & $19.4 \pm 1.1$ & $27.4 \pm 0.9$ & $18.5 \pm 0.6$ \\
\hline $3^{a}$ & $27.5 \pm 1.1$ & $26.5 \pm 0.7$ & $26.6 \pm 0.8$ & $26.8 \pm 2.1$ & $28.9 \pm 1.4$ & $27.1 \pm 0.8$ \\
\hline $4^{a}$ & $30.6 \pm 0.7$ & $19.0 \pm 1.2$ & $31.5 \pm 1.5$ & $18.6 \pm 1.2$ & $31.8 \pm 0.9$ & $18.9 \pm 0.7$ \\
\hline $5^{a}$ & $34.4 \pm 1.2$ & $10.2 \pm 0.4$ & $35.2 \pm 2.2$ & $10.7 \pm 0.7$ & $35.4 \pm 1.0$ & $10.1 \pm 0.6$ \\
\hline $6^{a}$ & $39.2 \pm 1.3$ & $19.0 \pm 2.1$ & $38.2 \pm 1.2$ & $19.9 \pm 1.2$ & $38.8 \pm 0.6$ & $19.4 \pm 0.4$ \\
\hline $\mathrm{SRM}^{\mathrm{b}}$ & $32.67 \pm 1.1$ & $0.151 \pm 0.005$ & & & & \\
\hline
\end{tabular}

a \% w/w $\mathrm{P}_{2} \mathrm{O}_{5}$ and $\mathrm{K}_{2} \mathrm{O}$ in samples: 20, 20 (\#1); 28, 20 (\#2); 28, 26 (\#3); 30, 20 (\#4); 35, 10 (\#5); 40, 20 (\#6).

b SRM: NIST 120c - Phosphate Rock: $(33.34 \pm 0.06) \% \mathrm{w} / \mathrm{w} \mathrm{P}_{2} \mathrm{O}_{5} ;(0.147 \pm 0.004) \% \mathrm{w} / \mathrm{w} \mathrm{K}_{2} \mathrm{O}$.

${ }^{\mathrm{c}}$ Emission lines for $\mathrm{P}$ and $\mathrm{K}$ at $213.618 \mathrm{~nm}$ and $766.490 \mathrm{~nm}$, respectively.

${ }^{\mathrm{d}}$ Molybdenum Blue Method.

${ }^{\mathrm{e}}$ Flame photometer with filter for $\mathrm{K}$ at $768 \mathrm{~nm}$.

\begin{tabular}{ccc}
\multicolumn{4}{c}{ TABLE V } \\
\multicolumn{3}{c}{ Recoveries (\%) for } \\
\multicolumn{2}{c}{ Spiked Fertilizer Samples } \\
\hline Sample & \multicolumn{2}{c}{ Recoveries (\%) } \\
& $\mathrm{P}$ & $\mathrm{K}$ \\
\hline 1 & 101 & 97 \\
2 & 98 & 98 \\
3 & 102 & 101 \\
4 & 99 & 99 \\
5 & 102 & 101 \\
6 & 98 & 98 \\
\hline
\end{tabular}

agreement with those obtained by ICP-OES, spectrophotometry, and F-AES at the $95 \%$ confidence levels.

Accuracy studies were carried out using recovery tests for liquid fertilizer samples spiked with $P$ and $K$. Recoveries of analytes added to diluted solutions of samples containing $450 \mathrm{mg} \mathrm{L}^{-1} \mathrm{~K}+1000 \mathrm{mg} \mathrm{L}^{-1} \mathrm{P}$ and $900 \mathrm{mg} \mathrm{L}^{-1} \mathrm{~K}+2000 \mathrm{mg} \mathrm{L}^{-1} \mathrm{P}$ varied within the $98-102 \%(\mathrm{P})$ and $97-101 \%(\mathrm{~K})$ intervals (Table V). The relative standard deviations $(\mathrm{n}=12)$ were $4 \%(\mathrm{P})$ and $2.2 \%(\mathrm{~K})$ for a fertilizer sample containing $875 \mathrm{mg} \mathrm{L}^{-1} \mathrm{P}$ and $850 \mathrm{mg} \mathrm{L}^{-1} \mathrm{~K}$. The limits of detection were $20.3 \mathrm{mg} \mathrm{L}^{-1}$ $P$ and $0.175 \mathrm{mg} \mathrm{L}^{-1} \mathrm{~K}(404.422 \mathrm{~nm})$. In spite of the fact that liquid fertil- izer samples contain high concentrations, nebulizer clogging was not observed. A long-term stability study was performed daily during 3-hour measurements of a diluted sample for 5 successive days.

The determination of $\mathrm{P}$ and $\mathrm{K}$ is better performed by simultaneous techniques such as ICP-OES. The fast-sequential measurements of several wavelengths by HR-CS FAAS make this the preferred technique over line source AAS. The total time for measuring two elements in triplicate by HR-CS FAAS is around 50 seconds. The most usual techniques for $\mathrm{P}$ and $\mathrm{K}$ determination in large-scale routine analysis of fertilizers are spectrophotometry and flame AES, respectively. But if an HR-CS FAAS spectrometer is available, it may be chosen because the consumption of reagent and the generation of residue may be reduced, which are favorable for "Green Chemistry". Besides, only a single sample preparation procedure and one technique are required for both $\mathrm{P}$ and $\mathrm{K}$ determination, making it an easier analytical task for fertilizer laboratories, saving time and reducing cost.

\section{CONCLUSION}

The side pixel registration approach and molecular absorption were employed for the determination of $\mathrm{P}$ and $\mathrm{K}$ in liquid fertilizers in a single run by high-resolution continuum source flame atomic absorption spectrometry (HR-CS FAAS). For the phosphorus oxide (PO) line at $327.040 \mathrm{~nm}$ and the alternative line for $\mathrm{K}$ at $404.422 \mathrm{~nm}$, analytical curves in the $100-5000$ $\mathrm{mg} \mathrm{L}^{-1} \mathrm{P}$ and 50-1000 $\mathrm{mg} \mathrm{L}^{-1} \mathrm{~K}$ ranges were obtained with good linear correlations. The proposed method was applied to the analysis of liquid fertilizers and the results were in agreement with those obtained by ICP-OES, UV/VIS and F-AES at the 95\% confidence level.

\section{ACKNOWLEDGMENTS}

The authors would like to thank the FAPESP and CNPq for financial support of this work and for fellowship to S.R.O. The authors are also grateful to CAPES and CNPq for the fellowships to R.B.F., V.P.F., A.V., and a research grant to J.A.G.N. (300600/2009-7).

$\overline{\text { Received September 24, } 2010 .}$ 


\section{Atomic \\ Vol. 32(2), March/April 2011}

\section{REFERENCES}

1. M.E. Farago, Plants and the Chemical Elements: Biochemistry, uptake, tolerance and toxicity, Wiley-VCH, Weinheim, Germany (1994).

2. D.C. Harris, Quantitative Chemical Analysis, 7rd ed., W.H. Freeman, New York, United States (2007).

3. Z. Marczenko, Separation and Spectrophotometric Determination of Elements, 2nd ed., Ellis Horwood, Chichester, United States (1986).

4. B. Welz and M. Sperling, Atomic Absorption Spectrometry, 3th ed., Wiley-VCH, Weinheim, Germany (1999).

5. P.W.J.M. Boumans, Inductively Coupled Plasma Emission Spectroscopy, Part 2, Applications and Fundamentals, 1st ed., Wiley-VCH, New York, United States (1987).

6. L.H.J. Lajunen, and P. Perämäki, Spectrochemical Analysis by Atomic Absorption and Emission, 2nd ed., RSC, Cambridge, London (2004).

7. M.D. Huang, H. Becker-Ross, S. Florek, U. Heitmann, and M. Okruss, J. Anal. At. Spectrom. 21, 338 (2006).

8. B. Welz, H. Becker-Ross, S. Florek, and U. Heitmann, High-Resolution Continuum Source AAS: The Better Way to Do Atomic Absorption Spectrometry, 1st ed., Wiley-VCH, Weinheim, Germany (2005).

9. J.L. Raposo Jr., S.R. Oliveira, N.M. Caldas, and J.A. Gomes Neto, Anal. Chim. Acta 627, 198 (2008).

10. S.R. Oliveira, J.L. Raposo Jr., and J.A. Gomes Neto, Spectrochim Acta, Part B 64, 593 (2009).

11. S. R. OLIVEIRA, J.A. GOMES NETO, J.A. NOBREGA, and B.T. JONES, Spectrochimica Acta, Part B 65, 316 (2010).

12. V.R. Amorim Filho, W.L. Polito, and J.A. Gomes Neto, At. Spectrosc. 25, 233 (2004).

13. L.A. Currie, Anal. Chim. Acta 391, 105 (1999). 